\title{
Erratum to: Elemental analysis of soils and Salix polaris in the town of Pyramiden and its surroundings (Svalbard)
}

\author{
Lucie Krajcarová $^{1,2} \cdot$ Karel Novotný ${ }^{1,3} \cdot$ Barbora Chattová $^{2,4}$ • Josef Elster ${ }^{2,5}$
}

Published online: 22 March 2016

(C) Springer-Verlag Berlin Heidelberg 2016

Erratum to: Environ Sci Pollut Res

DOI 10.1007/s11356-016-6213-4

The original publication of this paper contains a mistake. The correct affiliations are presented in this article.

The online version of the original article can be found at http://dx.doi.org/ 10.1007/s11356-016-6213-4.

Karel Novotný

codl@sci.muni.cz

1 Department of Chemistry, Faculty of Science, Masaryk University, Kotlářská 2, 61137 Brno, Czech Republic

2 Centre for Polar Ecology, Faculty of Science, University of South Bohemia, Na Zlaté Stoce 3, 37005 České

Budějovice, Czech Republic

3 Central European Institute of Technology, Masaryk University, Kamenice 5, 62500 Brno, Czech Republic

4 Department of Botany and Zoology, Faculty of Science, Masaryk University, Kotlářská 2, 61137 Brno, Czech Republic

5 Institute of Botany, Academy of Science of the Czech Republic, Dukelská 135, 37982 Třeboň, Czech Republic 